\title{
A anáfora direta no gênero digital comentário: a variação do nome (o referente) e seus determinantes condicionados à comunidade de prática no site Facebook
}

\section{The direct anaphora in the digital gender comment: the variation of the name (the reference) and its determinations conditioned to the community of practice on the Facebook site}

\author{
Cristina Normandia dos Santos ${ }^{*}$ \\ Centro de Ciências e Educação Superior à Distância do Estado do Rio de Janeiro \\ Rio de Janeiro, Rio de Janeiro, Brasil \\ Maria Teresa Tedesco Vilardo Abreu** \\ Universidade do Estado do Rio de Janeiro \\ Rio de Janeiro, Rio de Janeiro, Brasil
}

\begin{abstract}
Resumo: Atualmente, o uso da língua tem se realizado em situações comunicativas cada vez mais amplas e distintas, porque as necessidades de uso da língua acompanham o intenso ritmo das demandas sociais, como é o caso das inovações tecnológicas. É elementar o crescente uso da língua em gêneros digitais como nos comentários publicados no site Facebook, o qual é constituído por comunidades práticas, conceito proposto por Coelho, Görski, Souza e May (2015), que define o locus de fenômenos linguísticos utilizados por interactantes, em perfis públicos como os jornalísticos. Isso implica, interativamente $(\mathrm{KOCH}, 2002)$, a variação do nome (o referente) com base em anáforas diretas, significativas estratégias textuais (MONDADA; DUBOIS, 2003), que explicitam a ativação cognitiva pelo acionamento do conhecimento de mundo (DIJK, 2012). Compreender a variação do nome (o referente) pelo processo da anáfora direta, no gênero digital comentário, no Facebook, possibilita o entendimento da heterogeneidade do sistema, isto é, o uso coletivo da língua nessa atividade discursiva específica. Diante disso, Tedesco (2013) afirma que o princípio do continuum no uso da língua é balizado pelos gêneros discursivos, fator externo (COELHO et al., 2015), os quais refletem as escolhas linguísticas presentes no projeto de dizer. A partir de uma observação participante, numa perspectiva etnográfica, e da análise de conteúdo dos enunciados do gênero digital comentário, o presente trabalho visa determinar a variação do nome (o referente) em gênero digital comentário, no site Facebook, pois os dados analisados apontam para a variação dos referentes como recategorizadores encapsuladores e recategorizadores avaliativos. Os encapsuladores conotam que a variação do nome indica, de modo consciente, que o projeto de dizer utiliza uma referência generalizada na apresentação de ponto de vista. Enquanto o uso de recategorizadores avaliativos conota que a variação do nome implica um ponto vista subjetivo, o qual reflete uma inconsistência argumentativa do gênero digital comentário. Tais aspectos de variação do nome (referente) são importantes nos estudos sobre o uso coletivo da língua, que determina o propósito dos estudos sociolinguísticos.
\end{abstract}

Palavras-chave: Variação linguística. O nome. Anáfora direta. Gênero digital comentário.

\footnotetext{
*Professora do Centro de Ciências e Educação Superior à Distância do Estado do Rio de Janeiro. Rio de Janeiro, Brasil. E-mail: crnormandia@yahoo.com.br.

** Professora do Programa de Pós-Graduação em Letras - PPGLetras - Universidade do Estado do Rio de Janeiro, Rio de Janeiro, Rio de Janeiro, Brasil. E-mail: teresatedesco@uol.com.br.
} 


\begin{abstract}
Nowadays, the use of the language has been carried out in increasingly broad and distinct communicative situations, because the needs of language use follow the intense rhythm of social demands, as in the case of technological innovations. It is elementary the increasing use of the language in digital genres as in the comments published in the Facebook site, which is constituted by practical communities, concept proposed by Coelho, Görski, Souza and May (2015), that defines the locus of linguistic phenomena used by interactants, in public profiles such as journalism. This implies, interactively (KOCH, 2002), in the variation of the name (the referent) based on direct anaphora, a significant textual strategy (MONDADA; DUBOIS, 2003), which explicitly activates cognitive activation of world knowledge (DIJK, 2012). Understanding the variation of the name (the referent) through the process of direct anaphora, in the digital comment genre, on Facebook, enables the understanding of the heterogeneity of the system, that is, the collective use of language in this specific discursive activity. Tedesco (2013) affirms that the principle of the continuum in the use of the language is marked by the discursive genres, external factor (COELHO et al., 2015), which reflect the linguistic choices present in the project of saying. From a participant observation, ethnographic perspective, and still from the content analysis of the statements of the digital commentary, the present work aims to determine the variation of the name (the referent) in digital gender commentary, on the Facebook site, therefore, the analyzed data point to the variation of the referent with encapsulating recategorizers and evaluative recategorizers. The encapsulators connote that the variation of the name indicates, in a conscious way, that the project of saying uses a generalized reference in the presentation of point of view. While the use of evaluative recategorizers connotes that the name variation implies a subjective point of view, which reflects an argumentative inconsistency of the digital commentary. Such aspects of name (referential) variation are important in studies of the collective use of language that determines the purpose of sociolinguistic studies.
\end{abstract}

Keywords: Linguistic variation. The name. Direct anaphora. Digital genre comment.

\title{
1 INTRODUÇÃO
}

Contemporaneamente, as relações sociais dos indivíduos são realizadas a partir do uso da oralidade, do uso da escrita e do uso virtual da linguagem. Deste modo, é reconhecida uma terceira modalidade da linguagem, a qual está pautada no princípio do continuum, o qual é estabelecido entre as práticas sociais da linguagem. Tal reconhecimento desconsidera a afirmação de que a prática social da linguagem na Internet é pautada na modalidade escrita, como propõem Marcuschi e Xavier (2010). A modalidade escrita se desenvolve em condições comunicativas particulares, conforme gêneros discursivos mais elementares, como, por exemplo, o gênero bilhete, e mais complexos, como, por exemplo, o gênero conto. A modalidade virtual da linguagem, igualmente, é desenvolvida em gêneros discursivos digitais que refletem situações comunicativas mais elementares, como o gênero digital comentário, o qual está presente nas redes sociais e em Blogs, por exemplo, e mais complexas, como o gênero digital E-mail, com fins acadêmicos ou corporativos.

Nesse sentido, as condições de produção do texto, oral ou escrito ou virtual, são aspectos essenciais que influenciam no uso da língua, pois são forças existentes fora da língua que condicionam ou regulam as escolhas linguísticas, variações dentro da língua, durante a progressão discursiva (COELHO; GÖRSKI; SOUZA; MAY, 2015). Os gêneros discursivos são também fatores externos da língua que agem significativamente 
no uso da língua, em contextos diversos, e que devem ser considerados na análise de textos verbais.

Assim sendo, o presente estudo visa tratar do uso virtual da linguagem com base na rede social Facebook e no gênero digital comentário, os quais se caracterizam como condicionadores externos da língua, e na variação do nome, enquanto formas anafóricas diretas, uma variação considerada dentro da língua, no nível linguístico e discursivo.

Para esse fim, esta produção apresenta em sua segunda seção uma abordagem a respeito da rede social Facebook e do gênero digital comentário, fazendo, inicialmente, uma breve reflexão a respeito das comunidades virtuais - com Castells (1990), Lévy (2010) -, para, em seguida, destrinchar aspectos relacionados com o gênero digital comentário, começando pela modalidade virtual da linguagem, conforme as reflexões de Tedesco (2013) e Marcuschi (2003).

A abordagem sobre a influência cultural de redes sociais e sobre as características do gênero digital comentário permitem, na terceira seção, o tratamento sobre a anáfora direta e suas funções discursivas no texto verbal do gênero digital comentário, em diálogo com Koch (2002), Marcuschi (2012) e Tedesco (2012). Esta autora traz contribuições a respeito das funções discursivas das expressões anafóricas diretas, as quais refletem a variação do nome e de seus determinantes em expressões anafóricas diretas, questão de ordem gramatical que será apresentada na quarta seção do artigo.

Metodologicamente, as análises foram construídas como consequência de uma observação-participante, numa perspectiva etnográfica (FRAGOSO; RECUERO; AMARAL, 2016). A observação-participante ocorreu no perfil público da jornalista Eliane Cantanhêde, jornalista e comentarista política do jornal paulista O Estado de São Paulo. Em seu perfil público do Facebook, a jornalista publica seus artigos a respeito de temas relacionados com a política brasileira. O seu perfil no Facebook tem milhares de seguidores que, além de curtir as suas postagens, ainda publicam seus comentários. São os textos verbais desses comentários que vão permitir observar a variação linguísticodiscursiva do nome, pautada na estratégia anafórica direta. Isto posto, dá-se início à discussão.

\section{O FACEBOOKE O GÊNERO DIGITAL COMENTÁRIO}

O surgimento das redes sociais, com a expansão comercial da Internet, ampliou como as relações sociais são construídas e estabelecidas, contemporaneamente. Em todo o mundo, a sociedade, progressivamente, apreendeu uma interação a distância que ocorre de forma rápida, de estilo muito recreativo.

Querendo ou não, desconfiando ou não, seduzido ou não, o processo de globalização da economia nos fez reconhecer que a comunicação na Internet é um fato e, sendo um fato, está posto; estando posto, requer utilizá-la. Por isto, Castells (1990) e Lévy (2010), entre outros sociólogos e filósofos, se debruçaram sobre a comunicação que se realiza na Internet, com o fim de compreender as implicações culturais que esta comunicação gerou na sociedade. Uma das implicações culturais indicada por Castells (1990) é o surgimento de uma sociedade em rede: 
... embora as redes sejam uma antiga forma de organização na experiência humana, as tecnologias digitais de formação de redes, características da Era da Informação, alimentaram as redes sociais e organizacionais, possibilitando sua infinita expansão e reconfiguração, superando as limitações tradicionais dos modelos organizacionais de formação de redes quanto à gestão da complexidade de redes acima de uma certa dimensão. (CASTELLS, 1990, p. II)

Isto é, estabelecer redes de relacionamento é algo culturalmente comum na sociedade, como é o caso da organização de uma rede pautada nas relações familiares. Com as tecnologias digitais, houve uma expansão e reconfiguração das redes de relacionamento, conforme propõe o autor. As pessoas se organizam em redes sociais, na Internet, "ao redor de valores e interesses em comum" (CASTELLS, 1990, p. 442), o que implica a organização de grupos - redes - de pessoas que gostam de um estilo de música mais específico como o Rock, por exemplo, ou a organização de redes sociais com valores religiosos mais tradicionais, em que as pessoas trocam informações a respeito de suas convicções religiosas ou, igualmente, trocam informações que explicitam uma mesma convicção política e ideológica. Na verdade, as redes sociais ou comunidades sociais, na Internet, causam a construção de relações culturais entre iguais. O que gera obstáculos para o diferente e a consequência disto é uma sociedade cada vez mais organizada em guetos que podem possibilitar a exclusão cultural e social e também podem provocar conflitos entre os que pensam diferente, fato que gera preocupação de pesquisadores céticos à Internet. Tais aspectos são reais e preocupantes e merecem atenção constante, porque, apesar de ser uma interação coletiva, é uma coletividade que determina a homogeneidade de ideias.

Lévy (2010), um otimista em relação às relações sociais na Internet, pontua a importância de dois fatos sobre a sociedade em rede (CASTELLS, 1990), que é definida pelo autor como ciberespaço. O primeiro fato é que o ciberespaço foi desenvolvido por jovens que almejaram formas de comunicação coletiva, não centralizadas, as quais são distintas das mídias de comunicação tradicionais, como o rádio e a televisão, para se sentirem mais livres na comunicação das informações. O segundo fato é que o ciberespaço potencializou, positivamente, as relações sociais com propósito econômico, político, cultural e humano. São dois fatos que transformaram culturalmente a sociedade e que definem o conceito de cibercultura, proposto por Lévy (2010):

A cibercultura é a expressão da aspiração de construção de um laço social, que não seria fundado nem sobre links territoriais, nem sobre relações institucionais, nem sobre as relações de poder, mas sobre a reunião em torno de centros de interesses comuns, sobre o jogo, sobre o compartilhamento do saber, sobre a aprendizagem cooperativa, sobre processos abertos de colaboração. $\mathrm{O}$ apetite para as comunidades virtuais encontra um ideal de relação humana desterritorializadas, transversal, livre. As comunidades virtuais são os motores, os atores, a vida diversa e surpreendente do universal por contato. (LÉVY, 2010, p. 132-133)

Logo Lévy (2010) considera que, ao se reunir em redes sociais por interesses e valores comuns - de forma livre, sem gerenciamento das informações, compartilhadas 
coletivamente -, a sociedade se aproxima de um ideal que visa o coletivo, em que as comunidades virtuais e os atores sociais comandam as informações.

Tais aspectos permitiram o crescente consumo das redes sociais como o Twitter e os populares Facebook e Instagram. Todos com propósito tanto pessoal quanto público, que ficam expressos em textos verbais, não verbais e sonoros, em comentários publicados por interactantes nos ciberespaços de entretenimento. Recuero (2014) ainda destaca a importância de aspectos como as conexões e os atores, que estruturam as redes sociais:

Uma rede social é definida como um conjunto de dois elementos: atores (pessoas, instituições ou grupos; os nós da rede) e suas conexões (interações ou laços sociais) [...]. Uma rede é uma metáfora para observar os padrões de conexão de um grupo social, a partir das conexões estabelecidas entre os diversos atores. A abordagem de rede tem seu foco na estrutura social, onde não é possível isolar os atores sociais nem suas conexões. (RECUERO, 2014, p. 24)

Com o fim de exemplificação, o perfil público da jornalista Eliane Cantanhêde, na rede social Facebook, é constituído por pessoas que seguem e curtem o trabalho da jornalista, sendo ela e seus seguidores os atores da rede social, que estabelecem conexão com o objetivo do entretenimento de informações. A relação social num perfil público não apresenta o mesmo grau de afinidade presente em um perfil pessoal. Por isso, os perfis pessoais demandam privacidade, pois apenas pessoas convidadas são aceitas para fazerem parte da conexão pessoal, o que implica atores e laços sociais distintos de um perfil público, conforme o da jornalista do jornal O Estado de São Paulo, Eliane Cantanhêde.

É interessante observar que o jornalismo passou a utilizar as redes sociais com o fim de divulgação de notícias, de artigos opinativos, de notas jornalísticas e de vídeos. Uma vez publicados os fatos no Facebook, por exemplo, as informações são compartilhadas rapidamente, além de serem curtidas e também comentadas pelos interactantes. Tais usos da linguagem são essenciais, ultimamente, para manter a audiência de grandes empresas jornalísticas, pois as mesmas não detêm, unicamente, o poder da propagação da informação e o poder da formação da opinião, como pontuou Lévy (2010). A liberdade de manusear a informação era algo particular daqueles que compõem o universo jornalístico. Normalmente, o jornalismo filtra informações e expõe o que julga ser de interesse público.

No entanto há riscos diante dessa fluidez de informações nas redes sociais. Isso permite a circulação de informações falsas, as conhecidas Fakenews. Por isso, o respeitado filósofo Umberto Eco, em 2015, em sua premiação de "Doutor Honoris Causa", na Universidade de Turim, na Itália, criticou a manipulação da informação que ocorre nas redes sociais, pois qualquer indivíduo torna-se um propagador da informação, que pode ser falsa.

No entanto, com as necessárias ressalvas, o uso da linguagem no ciberespaço (LÉVY, 2010) é uma prática social da linguagem condizente com as especificidades do contexto digital e com as finalidades comunicativas de cada perfil de rede social. À vista disso, Tedesco (2013) observa que 
a interação, portanto, é essência da comunicação, "do se querer dizer". Logo as redes sociais, um dos tipos de esferas sociais existentes, exemplificam de forma plena esse processo. Cada esfera social terá seu tipo de enunciado; a esfera do trabalho tem seus enunciados específicos, assim com a escola, as artes, as ciências, as leis, as tecnologias, a internet e as redes sociais, de modo geral. Se existe uma ampliação dessas formas de comunicação, inclusive considerando os diferentes suportes, postula-se a possibilidade de reestruturação do que sejam as modalidades da língua. (TEDESCO, 2013, p. 480)

O gênero discursivo digital comentário é um uso da linguagem que reflete a interação, a comunicação, o "querer dizer" mencionado por Tedesco (2013). Este é um uso da linguagem que apresenta características particulares e comuns com outros usos da linguagem, refletindo, assim, o processo continum entre as modalidades da linguagem. Logo este uso da linguagem apresenta particularidades linguísticas como:

a) uso de recursos verbais não lexicalizados (ahamm);

b) uso de recurso suprassegmental do tipo repetição de vogal no final das palavras (queroooo, lindaaa);

c) uso de recurso suprassegmental (pontuação - arrasou!!!!!);

d) uso de recurso paralinguístico (os emoticons);

e) uso de frases nominais (Linda!!);

f) uso de períodos simples e compostos por coordenação.

Entre as particularidades discursivas, o uso da linguagem em comentários no Facebook apresenta: o aspecto hipertextual (não linear), o aspecto híbrido (texto verbal, não verbal e sonoro), a intertextualidade, a troca de turnos, a interação, a distância.

O aspecto hipertextual está relacionado com o nível macrodiscursivo; dessa forma, o gênero digital comentário é uma superestrutura discursiva. Portanto o nível microdiscursivo do gênero comentário estabelece uma relação com outro texto que lhe serve de fonte, o que determina as relações de intertextualidade, como pode ser observado no exemplo 1, em que o texto fonte é um recorte do artigo da jornalista Cantanhêde, "Governo usa aids contra a maioridade penal", publicado em seu perfil do Facebook, em 2015, o qual é a matriz do comentário da interactante Susi:

Exemplo 1: "Governo usa aids contra a maioridade penal" e comentário de Susi ${ }^{1}$

A taxa de contaminação por aids no sistema prisional brasileiro é $60 \%$ superior à taxa na população total do País. São 1.215 contaminados a cada cem mil presidiários, contra 20,2 por cem mil fora das prisões.

Os dados fazem parte de um detalhado estudo que será divulgado oficialmente nesta segunda-feira, 22, pelo ministro da Justiça, José Eduardo Cardozo, em sua cruzada contra os projetos em tramitação no Congresso para a redução da idade penal de 18 para 16 anos.

1 Retirado de: https://www.facebook.com/pg/elianecantanhedejornalista/posts/?ref=page internal. O artigo de opinião e os comentários com o mesmo relacionado serão utilizados nos exemplos desta discussão. 
“Está evidente que um jovem que entrar no sistema carcerário terá uma propensão muitíssimo maior de sair de lá com aids. Se é que vai conseguir sair vivo de lá”, disse o ministro à reportagem.

Além da questão de saúde, Cardozo aponta outros problemas graves da eventual redução da maioridade penal, em fase de votação pela Câmara dos Deputados. Um deles é a da superlotação dos presídios.

"O sistema vai explodir. Aliás, o sistema já está explodido”, disse o ministro, estimando que, caso a redução seja aprovada, esse sistema será sobrecarregado a cada ano por mais 40 mil jovens que responderem por apenas um tipo de crime, o tráfico de drogas. Ele explicou que os projetos em estudo preveem a redução no caso de crime hediondo. O tráfico é enquadrado nessa categoria.

\section{Comentário da interactante Susi²:}

Eu não acredito que o ministro disse td isso... tem consciencia de TODOS os problemas. Não coloca o que está sendo feito ou fará para melhoria no sistema carcerário... e defende então que criminosos fiquem soltos... assim... pq são menores... deixe os à margem da lei... praticando crimes... pq o governo não tem projeto ou solução para seus problemas... mas que báh!!! O ultimo q sair apaga a luz... que pais é este???

O artigo da jornalista Cantanhêde trata da redução da maioridade penal, em que a nova proposta prevê a redução da idade de menores infratores, de 18 anos para 16 anos. É um projeto polêmico, com opiniões divergentes, de modo que a jornalista Cantanhêde apresenta em seu artigo a opinião do, então, Ministro José Eduardo Cardozo, o qual se opunha à redução da idade penal, pautado no argumento a respeito do aumento dos casos de aids no sistema prisional brasileiro. Nesse sentido, os interactantes, como a participante Susi, opinam a respeito do tema abordado no artigo, estabelecendo, assim, uma relação intertextual temática, comprovada pela reativação de informações do artigo na superfície textual do comentário, as quais estão grifadas nos dois textos e são, novamente, especificadas a seguir:

A) Artigo de opinião: informações tópicas = sistema prisional brasileiro, Ministro da Justiç, um jovem, um tipo de crime.

B) Comentário de Susi = o ministro, sistema carcerário, menores, crimes.

A relação intertextual temática entre o artigo de opinião e o comentário de Susi determina a existência de uma superestrutura discursiva que reflete a natureza hipertextual do gênero comentário. A natureza hipertextual do gênero comentário permite constatar a relação à distância entre os interactantes na rede social Facebook e a troca de turnos, pois, abaixo, fica sinalizado há quanto tempo o comentário e também os textos que servem de

${ }^{2}$ Retirado de: https://www.facebook.com/pg/elianecantanhedejornalista/posts/?ref=page internal. 


\section{Revista

matriz para os comentários foram publicados. Estas são particularidades macrodiscursivas da superestrutura gênero digital comentário.

É importante observar que o comentário da interactante Susi é estruturalmente verbal. No entanto, de acordo com o propósito comunicativo e a situação comunicativa, os interactantes podem usar a linguagem não verbal e sonora em seus comentários na rede social Facebook. Estes usos da linguagem são recorrentes no Facebook e podem ser exemplificados pela publicação de Memes e de fotos de interactantes. Por isso, a comunicação nas redes sociais apresenta a particularidade de ser híbrida, pois o uso da linguagem é desenvolvido, concomitantemente ou não, de forma verbal, não verbal e sonora, a depender do propósito comunicativo e da situação comunicativa em que se organiza o "projeto de dizer" (TEDESCO, 2013), tal como o exemplo do Meme a seguir:

Figura 1: Meme

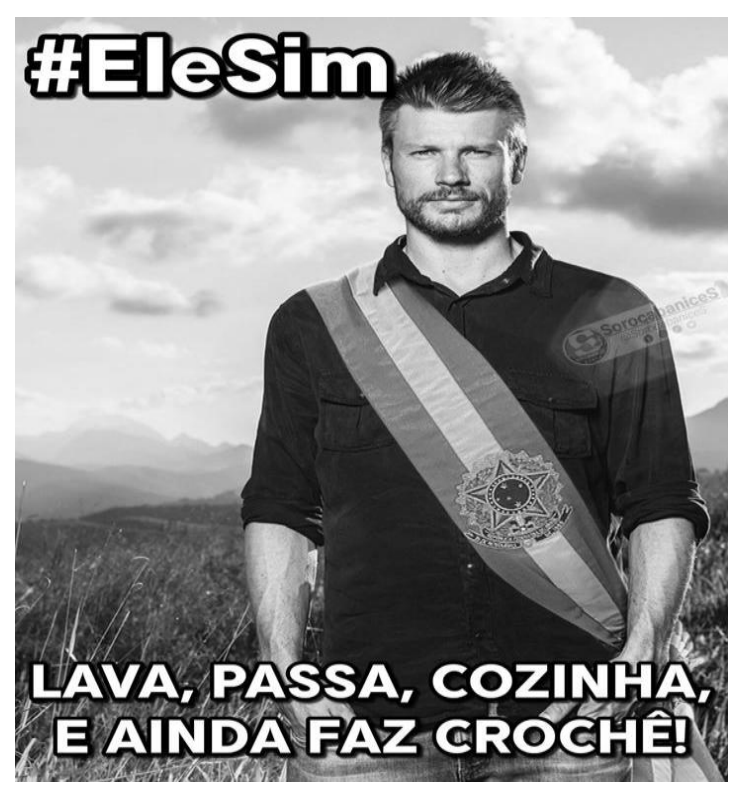

O Meme acima representa um uso híbrido da linguagem, de modo verbal e não verbal, cujo propósito comunicativo é satirizar uma manifestação política, nas redes sociais, organizada por mulheres, que propunha a não votação no candidato Jair Bolsonaro, em 2018, por seu discurso de teor machista. O conteúdo da campanha era \#Elenão. Em contrapartida, o Meme propõe o \#Elesim, em que o ator Rodrigo Hilbert está com a faixa presidencial, seguido de texto verbal: "LAVA, PASSA, COZINHA, E AINDA FAZ CROCHÊ!!”. Há, no Meme, também um posicionamento de ordem feminista, mas com propósito comunicativo de satirizar o contexto político do momento. O uso não verbal da linguagem nas redes sociais tem outras possibilidades, além de Memes e de imagens (fotos): os emoticons e símbolos populares como o que simboliza a ação de curtir, no Facebook. Estes são usos de linguagem muito significativos e expressivos os quais apresentam uma temática própria, um estilo e uma estrutura organizacional concernentes 
com a comunicação não verbal, portanto são considerados gêneros discursivos do contexto digital. Dessa forma, Bakhtin (2010) postula que

os gêneros do discurso, comparados às formas da língua, são bem mais mutáveis, flexíveis e plásticos; entretanto, para o indivíduo falante, eles têm significado normativo, não são criados por ele mas dados a ele. Por isso um enunciado singular, a despeito de toda a sua individualidade e do caráter criativo, de forma alguma pode ser considerado uma combinação absolutamente livre de formas da língua, como supõe, por exemplo, Saussure (e muitos outros linguistas que o secundam), que contrapõe enunciado (la parole) como ato puramente individual ao sistema da língua como fenômeno puramente social e obrigatório para o indivíduo. (BAKHTIN, 2010, p. 285)

O uso da linguagem em comentários publicados na rede social Facebook demonstra o quanto a língua é mutável, flexível, criativa e plástica para acompanhar as transformações sociais e culturais ocorridas na comunicação digital. Isso posto, na seção seguinte, inicia-se o tratamento do texto verbal no gênero digital comentário com o fim de tratar da variação do nome em expressões anafóricas diretas. Para tal objetivo, será feita uma consideração a respeito da estratégia textual anáfora direta e suas funções discursivas com Koch (2002), Tedesco (2002) e Marcuschi (2013), exemplificadas com comentários relacionados com o artigo de opinião "Governo usa aids contra a maioridade penal”, de Cantanhêde, publicado no perfil da jornalista, no Facebook, em 2015.

\section{A ANÁFORA DIRETA: A ORDEM MICRODISCURSIVA NO GÊNERO COMENTÁRIO}

$\mathrm{Na}$ seção anterior, foi realizada uma reflexão a respeito das redes sociais e da influência cultural que estas geraram na sociedade, de acordo com Lévy (2010) e Castells (1990), de forma a explicitar a influência dessas comunidades virtuais no processo de interação social, a qual é realizada por meio do uso virtual da linguagem. Uso este que mantém em suas propriedades linguísticas e discursivas o aspecto continuum das modalidades da linguagem, a fim de atender aos propósitos comunicativos e às situações comunicativas inerentes aos ambientes virtuais de entretenimento. Sendo assim, o uso virtual da linguagem, além de apresentar características comuns relacionadas com a modalidade oral, como a informalidade e a troca de turnos, e com a modalidade escrita, a utilização da pontuação e a interação a distância, também apresenta as suas particularidades linguístico-discursivas, entre as quais: o hibridismo textual (verbal, não verbal e sonoro), a hipertextualidade, a intertextualidade e a interatividade, presentes em práticas discursivas digitais, tal como o gênero digital comentário, apresentado na seção anterior.

Na seção atual, é iniciada a discussão do texto verbal, a estrutura linguística, a partir da estratégia textual anáfora direta, que permitirá a compreensão da variação do nome e de seus determinantes, enquanto núcleo de sintagmas nominais, no gênero digital comentário. 
Koch (2002) observa que, durante o processamento textual, ocorrem operações textuais, as quais orientam para atividades discursivas de ativação, reativação e de-ativação de informações. Essas atividades determinam a progressão referencial, que se desenvolve a partir da anáfora e da catáfora. A anáfora é definida como uma referência textual endofórica e a catáfora é uma referência textual exofórica (KOCH, 1999). Assim, a estratégia textual catafórica se constrói a partir de uma projeção de um referente, logo é uma operação textual estabelecida em um movimento "para frente", enquanto a estratégia anafórica estabelece a ativação, a reativação e a de-ativação de referentes textuais na superfície do texto.

Sendo assim, a operação anafórica tipifica-se numa atividade discursiva direta e indireta. A anáfora direta é uma operação discursiva de correferência, logo há a ativação e a reativação de referentes na superfície textual com perfil direto, enquanto a anáfora indireta é uma operação discursiva de inserção de novas informações no horizonte do texto, as quais estabelecem relações semânticas indiretas com os referentes do texto, por isso é discursiva e especificada como uma operação de de-ativação (KOCH, 2002).

A anáfora direta é uma operação textual, logo coesiva, em que se efetua o processo de (re)construção do referente textual. Dessa maneira, ao ser ativado no texto, o referente passa a ocupar um endereço cognitivo, conforme explica Koch (2002), para em algum momento ser reativado, com o fim de possibilitar a produção de sentidos do texto.

A reconstrução é a operação responsável pela manutenção em foco, no modelo de discurso, de objetos previamente introduzidos, dando origem às cadeias referenciais ou coesivas, responsáveis pela progressão referencial do texto. Pelo fato de o objeto encontrar-se ativado no modelo textual, ela pode realizar-se por meio de recursos de ordem gramatical (pronomes, elipses, numerais, advérbios locativos etc.) bem como por intermédio de recursos de ordem lexical (reiteração de itens lexicais, sinônimos, hiperônimos, nomes genéricos, expressões nominais etc.). (KOCH, 2014, p. 38)

Nesse sentido, Marcuschi (2012) observa que a anáfora direta não é simplesmente uma básica operação discursiva de retomada de um referente anteriormente ativado no texto. Esta é uma operação cognitiva muito significativa, pois determina a progressão semântica do texto e reflete a heterogeneidade existente no discurso. Isso pode ser visualizado no exemplo de comentário do interactante Marcos, a respeito do artigo de opinião da jornalista Cantanhêde, "Governo usa aids contra a redução da maioridade penal”, já anteriormente exemplificado:

\section{Exemplo 2: Comentário do interactante $\operatorname{Marcos}^{3}$}

Está evidente que um jovem que entrar no sistema carcerário terá uma propensão multíssimo maior de sair de lá com aids. Se é que vai conseguir sair vivo de lá, disse o ministro à reportagem. Esse ministrinho, só fala besteira, e as vítimas mortas por esses bandidos? E as famílias dessas vítimas? Eles não contam. Ridículo esse senhor.

\footnotetext{
${ }^{3}$ Retirado de: https://www.facebook.com/pg/elianecantanhedejornalista/posts/?ref=page internal.
} 
$\mathrm{Na}$ superfície textual do artigo de opinião "Governo usa aids contra a redução da maioridade penal", com função discursiva que serve de texto-fonte para os comentários dos interactantes, têm-se os seguintes referentes textuais ativados: 'Ministro da justiça', 'sistema prisional brasileiro', 'um jovem' e 'redução da maioridade penal'. Por consequência da relação discursiva, no texto verbal do comentário de Marcos, os referentes textuais 'um jovem', 'sistema prisional brasileiro' e 'Ministro da justiça' são reativados, de modo a serem construídas cadeias anafóricas diretas seguintes:

a) referente 'um jovem' (ativado no texto-fonte):

Um jovem (reativado no comentário) $\leftrightarrow$ esses bandidos (comentário).

b) referente 'Sistema prisional brasileiro' (ativado no texto-fonte): há apenas uma reativação no comentário de Marco com a forma anafórica direta 'Sistema carcerário’.

c) referente 'Ministro da justiça' (ativado no texto-fonte):

O ministro (reativado no comentário) $\leftrightarrow$ esse ministrinho (comentário) $\leftrightarrow$ ridículo esse senhor (comentário).

As cadeias anafóricas diretas, o nível microdiscursivo, confirmam que o gênero digital comentário é uma superestrutura discursiva o qual estabelece relação hipertextual, nível macrodiscursivo, com o artigo da jornalista Cantanhêde. Essas mesmas cadeias anafóricas diretas também orientam para as relações intertextuais (explícita e implícita) construídas entre o comentário de Marcos e o artigo da jornalista. Portanto é qualificada como uma superestrutura discursiva, em que as propriedades linguísticas e discursivas confirmam a heterogeneidade do discurso (KOCH, 2002) dessa comunicação digital, conforme se constata nas reativações dos referentes discursivos - 'um jovem', 'sistema prisional brasileiro' e 'Ministro da justiça' -, nas cadeias anafóricas diretas.

Tedesco (2002) propõe que as formas anafóricas diretas exercem funções discursivas específicas no processo de progressão do referente na cadeia anafórica. A primeira função discursiva é a introdução do referente discursivo na cadeia anafórica, a qual é compreendida pela operação de ativação de referente discursivo que passa a ocupar um endereço cognitivo na superfície textual. Os referentes discursivos 'um jovem', 'Ministro da justiça' e 'sistema prisional brasileiro' foram introduzidos no artigo da jornalista Cantanhêde de maneira a ocuparem um endereço cognitivo, segundo propõe Koch (2002), para uma reativação discursiva.

A segunda função discursiva proposta por Tedesco (2002) é a manutenção do referente discursivo, quando há na cadeia anafórica a manutenção do núcleo do referente, conforme a reativação do referente textual sistema prisional, no comentário de outro interactante de nome Paulo: 


\section{Exemplo 3: Comentário do interactante Paulo ${ }^{4}$}

Estão fazendo de tudo para não reduzir, inclusive assumirem as péssimas condições do sistema prisional como desculpa. Agora, reformar o sistema prisional, nem brincando.

O exemplo 3 apresenta a introdução ou a primeira menção do referente textual 'as péssimas condições do sistema prisional', que é reativado pela função discursiva de manutenção do nome 'sistema prisional'. É importante observar que 'as péssimas condições do sistema prisional' é uma reativação do referente textual 'sistema prisional brasileiro', ativado no texto-fonte "Governo usa aids contra a redução da maioridade penal".

A terceira função discursiva proposta por Tedesco (2002) é a retomada de item lexical, que, segundo a autora, não ocorre de modo subsequente. A cadeia anafórica do referente textual Ministro da justiça, no artigo de opinião (texto-fonte), explicita a operação cognitiva de retomada do referente textual, que não ocorre de modo subsequente:

Exemplo 4: cadeia anafórica do referente Ministro da justiça (texto-fonte)

Ministro da justiça (Introdutor $-2^{\circ}$ parágrafo) $\leftrightarrow$ José Eduardo Cardozo $\left(2^{\circ}\right.$ parágrafo $) \leftrightarrow$ em sua cruzada $\left(2^{\circ}\right.$ parágrafo $) \leftrightarrow$ o ministro ( $3^{\circ}$ parágrafo $) \leftrightarrow$ Cardozo $\left(4^{\circ}\right.$ parágrafo $) \leftrightarrow$ o ministro $\left(5^{\circ}\right.$ parágrafo $) \leftrightarrow$ ele $\left(5^{\circ}\right.$ parágrafo $) \leftrightarrow$ ele $\left(6^{\circ}\right.$ parágrafo $) \leftrightarrow$ ele ( $6^{\circ}$ parágrafo $) \leftrightarrow$ José Eduardo Cardozo ( $7^{\circ}$ parágrafo $) \leftrightarrow$ ele ( $8^{\circ}$ parágrafo $) \leftrightarrow$ segundo ele ( $8^{\circ}$ parágrafo $) \leftrightarrow$ Cardozo $\left(9^{\circ}\right.$ parágrafo $) \leftrightarrow$ o ministro $\left(9^{\circ}\right.$ parágrafo $) \leftrightarrow$ na sua opinião ( $9^{\circ}$ parágrafo $) \leftrightarrow$ o ministro $\left(10^{\circ}\right.$ parágrafo $)$

Há, na cadeia do referente textual Ministro da justiça, a primeira menção no segundo parágrafo - 'Ministro da justiça' - e no terceiro parágrafo ocorre a manutenção do núcleo do referente textual - o ministro -, e o mesmo sintagma nominal é retomado ou repetido nos $5^{\circ}, 9^{\circ}$ e $10^{\circ}$ parágrafos.

A quarta função discursiva desempenhada por formas anafóricas diretas é a recategorização, em que, segundo Tedesco (2002), a forma anafórica mantém o sentido básico do referente textual introduzido na cadeia anafórica. O exemplo 2, o comentário da interactante Marcos, apresentado anteriormente, mostra a recategorização do referente textual 'sistema prisional brasileiro' com a forma anafórica direta 'sistema carcerário'. O item lexical 'carcerário' é usado como um sinônimo do item lexical 'prisional', o que amplia a progressão do referente textual e evita-se a repetição do adjetivo 'prisional'.

A última função discursiva apontada por Tedesco (2002) é a recategorização avaliativa, que apresenta um grau de subjetividade e que reflete a opinião do produtor do texto com a intenção de persuadir o interlocutor. Ainda fazendo referência ao comentário

${ }^{4}$ Retirado de: https://www.facebook.com/pg/elianecantanhedejornalista/posts/?ref=page internal. 
do exemplo 2, este é constituído pelas formas anafóricas recategorizadoras avaliativas 'esse ministrinho' e 'ridículo esse senhor', os quais orientam para o ponto de vista do interactante Marco, que avalia o referente textual 'Ministro da justiça'. Essa avaliação determina o sentido de contrariedade na opinião de Marco. Outro exemplo é o comentário da interactante Sonia, em que o referente textual 'um jovem' é recategorizado avaliativamente:

\section{Exemplo 5: Comentário da interactante Sonia ${ }^{5}$}

Estou impressionada com os argumentos usados para justificar que bandidos continuem soltos. Se o sistema prisional não presta, se está abarrotado de criminosos a solução é deixar os bandidos menores de 18 anos soltos, apavorando a sociedade??? E agora ainda colocam a AIDS como obstáculo à prisão dos menores bandidos. Bandido que mata, estupra, sequestra, etc. tem que ser preso não importa a idade que tenha. E do mesmo modo que a maioria dos menores não são bandidos, ouso dizer que a maioria dos que são bandidos dificilmente vão se regenerar. Outra coisa, prisioneiro não tem que ficar recluso sem fazer nada como acontece nas prisões brasileiras, eles têm que trabalhar pra se manter e estudar.

Forma-se no comentário de Sonia uma cadeia anafórica direta para o referente textual 'um jovem' constituída por recategorizadores avaliativos (RA) e não avaliativos (REC), a qual é apresentada a seguir:

Um jovem $\leftrightarrow$ bandidos $(\mathrm{RA}) \leftrightarrow$ criminosos $(\mathrm{RA}) \leftrightarrow$ os bandidos menores de 18 anos (RA) $\leftrightarrow$ menores bandidos (RA) $\leftrightarrow$ bandido (RA) $\leftrightarrow$ a maioria dos menores (REC.) $\leftrightarrow$ bandidos $(\mathrm{RA}) \leftrightarrow$ eles (retomada).

A cadeia anafórica direta do referente textual 'um jovem' explicita que, no texto verbal do comentário de Sonia, a recategorização avaliativa é a função discursiva predominante, o que aumenta o valor persuasivo do ponto de vista da interactante Sonia.

Diante do exposto, observa-se que a anáfora direta é uma estratégia textual muito importante não apenas para a progressão do texto mas também para o processo de significação do texto, de modo a evidenciar o propósito comunicativo dos comentários publicados no Facebook. Além disso, a estratégia anafórica direta, na estrutura textual dos comentários, indica a vinculação temática da estrutura verbal destes com o texto que lhes serve de fonte ou matriz - o artigo da jornalista Cantanhêde.

$\mathrm{Na}$ próxima seção, será realizada uma análise mais particular de expressões anafóricas diretas nas funções discursivas de recategorização e de recategorização avaliativa, em que será observada a variação do nome nas formas anafóricas diretas especificamente, a variação de perfil lexical e de perfil sintático no sintagma nominal.

${ }^{5}$ Retirado de: $\underline{\text { https://www.facebook.com/pg/elianecantanhedejornalista/posts/?ref=page internal. }}$. 


\section{A VARIAÇÃO DO NOME EM FORMAS ANAFÓRICAS DIRETAS}

$\mathrm{Na}$ seção anterior, foi abordada a estratégia textual anáfora direta e as funções discursivas desempenhadas pelas mesmas, segundo as postulações de Tedesco (2002). Nas funções discursivas de recategorização e de recategorização avaliativa do núcleo do referente discursivo - o nome - e seus determinantes, há mudanças significativas que ampliam tanto a argumentação dos textos verbais como a persuasão dos pontos de vista dos interactantes. Isso contribui para reconhecer as nuances discursivas da comunicação digital que se efetua com o uso virtual da linguagem.

Nos comentários analisados, neste estudo, observa-se que os interactantes que curtem e seguem a jornalista Cantanhêde, em seu perfil público do Facebook, apresentam um nível cultural amplo, de modo que utilizam, abrangentemente, os recursos da língua na exposição de seus pontos de vista. Entre os recursos, salientam-se variações de ordem gramatical, como a mudança de classe das palavras, e a ampliação semântica de palavras, consoante a adição de afixos ao radical. Destacam-se, especificamente, as mudanças gramaticais acontecidas no nome, enquanto núcleo de formas anafóricas recategorizadoras avaliativas ou não, ou em palavras com função de determinante, como é o caso dos adjetivos. A variação do determinante, inclusive, pode levar ao surgimento de um subtópico, o qual mantém relações discursivas com tópicos discursivos na progressão textual. Seriam formas anafóricas diretas encapsuladoras, por meio das quais, segundo Conte (2003, p.177), "um sintagma nominal funciona como uma paráfrase".

O nível cultural pode ser considerado, sociolinguisticamente, uma variedade relacionada ao critério social, pois o nível cultural de um usuário da língua demonstra a influência do fator escolaridade, o qual é um dos aspectos sociais que caracteriza a fala ou a escrita ou também o uso virtual da linguagem das pessoas. Por isso, quanto maior o nível cultural do indivíduo, mais este utilizará os recursos linguísticos com maior competência discursiva - competência que possibilita o usuário compreender as variações da língua em contextos sociais diversificados, conforme é exemplificado com o contexto social das redes sociais, entre estas o Facebook. De acordo com Coelho, Görski, Souza e May (2015),

de fato, palavras ou construções em variação, em vez de comprometerem o mútuo entendimento, são ricas em significado social e têm o poder de comunicar a nossos interlocutores mais do que o significado referencial/representacional pelo qual "disputam". As diferentes formas que empregamos ao falar e ao escrever dizem, de certo modo, quem somos: dão pistas a quem nos ouve ou lê sobre o local de onde viemos, o quanto estamos inseridos na cultura letrada dominante de nossa sociedade, quando nascemos, com que grupo nos identificamos, entre várias outras informações. (COELHO; GÖRSKI; SOUZA; MAY, 2015, p. 16)

Tal percepção se distancia da visão dicotômica da língua, que, para Marcuschi (2003, p. 27), é "uma análise que se volta para o código e permanece na imanência do fato linguístico". Nesse viés, a fala e a escrita apresentam características muito específicas que não consideram a influência de fatores sociais e geográficos, os quais apresentam suas variedades associadas ao contexto de uso. Aliás, o conceito de uso não encontra sentido 
na percepção dicotômica, porque o sentido de uso apresenta significação social. Marcuschi (2003) diz que

a perspectiva da dicotomia estrita oferece um modelo muito difundido nos manuais escolares, que pode ser caracterizado como a visão imanentista que deu origem à maioria das gramáticas pedagógicas que se acham hoje em uso. Sugere dicotomias estanques com separação entre forma e conteúdo, separação entre língua e uso e toma a língua como sistema de regras, o que conduz o ensino de língua ao ensino de regras gramaticais. (MARCUSCHI, 2003, p. 28)

No entanto o uso formal da língua, nas modalidades falada, escrita e virtual, submete-se a um padrão que é determinado pelo contexto social, porque a "língua é um fato social", como defendeu Calvet (2002, p. 33). Portanto não há como considerar a forma da língua dissociada do seu uso. Não há como considerar as particularidades do uso da língua em redes sociais sem analisá-las em seu contexto de uso, por exemplo, o Facebook. O uso da linguagem em redes sociais levou a que visões mais prescritivas o conceituassem como 'internetês', escrita da Internet que compromete o padrão da escrita formal, porque busca reproduzir a modalidade falada - visão que desconsidera a língua como interação e o texto como lugar de interação da linguagem.

Segundo Tedesco (2013, p. 479), "nessa interação em que a língua é (re)construída no discurso, no uso, os signos linguísticos são variáveis em enunciados concretos produzidos pelos sujeitos sociais, sendo a língua o próprio lugar de interação dos sujeitos".

Assim, no Facebook, o contexto discursivo de uso da língua é particularizado, porque existem no site dois perfis de entretenimento - o pessoal e o público - o que acarreta especificidades como a temática e o estilo, que vão demandar um uso padrão ou não padrão, submetidos a uma norma no processo de interação da linguagem. Por isso, Calvet (2003, p. 143) diz: "o objeto de estudo da linguística não é apenas a língua, mas a comunidade social sob seu aspecto linguístico”. No Facebook, os perfis são as comunidades virtuais organizadas que normatizam o padrão e o não padrão no uso da língua.

Nesse sentido, linguisticamente, a estratégia textual anáfora direta é um importante aspecto para observação do uso virtual da linguagem, porque, gramaticalmente, a estratégia textual é concretizada a partir do uso de pronomes de terceira pessoa (singular e plural), do uso de elipses e do uso de sintagmas nominais simples e complexos, definidos por Koch (2002) como expressões anafóricas definidas e indefinidas. Os sintagmas nominais são estruturalmente organizados com o nome, o núcleo do sintagma, o qual, sintaticamente, se relaciona com outros vocábulos que, no sintagma, possuem a função de determinantes. É o caso dos pronomes adjetivos, dos artigos e dos adjetivos.

O nome representa, linguisticamente, o núcleo do sintagma nominal com função de objeto discursivo, que vai se (re)construindo com a progressão textual. Nesse processo de (re)construção, o nome e seus determinantes passam por variações de ordem gramatical, em que pode ocorrer a mudança de classe destes ou ainda a ampliação semântica do núcleo do sintagma. Tudo isso é possibilitado pelo conhecimento linguístico do usuário da língua, que visa atender às particularidades do contexto social, tal como as redes de entretenimento. Koch (2002) postula que 
o conhecimento linguístico compreende o conhecimento gramatical e o lexical, sendo o responsável pela articulação som-sentido. É ele o responsável, por exemplo, pela organização do material linguístico na superfície textual, pelo uso dos meios coesivos que a língua nos põe à disposição para efetuar a remissão ou a sequenciação textual, pela seleção lexical adequada ao tema e/ou aos modelos cognitivos ativados. (KOCH, 2002, p. 48)

Por isso, a variação lexical em sintagmas nominais, nas funções discursivas de recategorização e de recategorização avaliativa, determina que o usuário da língua faz, cognitivamente, uma seleção lexical adequada para atender às singularidades temáticas. Por exemplo, o referente 'Ministro da justiça', em sua progressão no comentário do interactante Marcos, amplia o sentido semântico do núcleo:

\section{Exemplo 6: comentário de Marcos ${ }^{6}$}

Está evidente que um jovem que entrar no sistema carcerário terá uma propensão multíssimo maior de sair de lá com aids. Se é que vai conseguir sair vivo de lá, disse o ministro à reportagem. Esse ministrinho, só fala besteira, e as vítimas mortas por esses bandidos? E as famílias dessas vítimas? Eles não contam. Ridículo esse senhor.

$\mathrm{Na}$ forma anafórica recategorizadora avaliativa 'esse ministrinho', o nome - núcleo do sintagma nominal - sofre variação a partir do processo de derivação sufixal, com a adição do sufixo diminutivo -inho, o qual, além do sentido diminutivo, orienta para o valor pejorativo, com a intenção de ironizar e criticar o referente discursivo 'Ministro da Justiça'. Segundo Basílio (2003, p. 8), "o diminutivo é usado sobretudo para adicionar ao significado de uma palavra uma referência a uma dimensão pequena (sapato/sapatinho), para sinalizar uma linguagem afetiva (sopa/sopinha) ou para expressar a pejoratividade (argumento/argumentozinho)".

Por esse motivo, a pejoratividade do diminutivo em 'Ministrinho' - núcleo do SN - ganha importância e destaque nessa recategorização avaliativa, porque tal escolha linguística, que se qualifica como uma variação lexical, orienta para o posicionamento ideológico de Marcos e também para o nível cultural do usuário da língua. O diminutivo em 'Ministrinho' amplia a argumentatividade do comentário, devido ao seu valor persuasivo. A persuasão é um aspecto procurado pelos interactantes em gêneros discursivos digitais, assim como o gênero comentário. Agora, se observa outro exemplo de derivação do nome, que, no comentário da interactante Susi, apresenta status de subtópico:

\section{Exemplo 7: Comentário de Susi ${ }^{7}$}

Eu não acredito que o ministro disse td isso... tem consciencia de TODOS os problemas. Não coloca o que está sendo feito ou fará para melhoria no sistema

\footnotetext{
${ }^{6}$ Retirado de: https://www.facebook.com/pg/elianecantanhedejornalista/posts/?ref=page internal.

${ }^{7}$ Retirado de: https://www.facebook.com/pg/elianecantanhedejornalista/posts/?ref=page internal.
} 
carcerário... e defende então que criminosos fiquem soltos... assim... pq são menores... deixe os à margem da lei... praticando crimes... pq o governo não tem projeto ou solução para seus problemas... mas que báh!!! O ultimo q sair apaga a luz... que pais é este???

No comentário de Susi, há a palavra 'criminosos' que é uma recategorização avaliativa do referente discursivo 'um jovem'. O recategorizador avaliativo 'criminosos' é palavra derivada de 'crime'. A importância discursiva de crime no comentário de Susi está relacionada com o referente discursivo ‘jovem'. Por essa razão, no comentário, 'crimes' torna-se um referente discursivo, como consequência do uso do recategorizador avaliativo 'criminosos'. O aspecto curioso do exemplo 6 é que a palavra 'crimes', definida, gramaticalmente, como a raiz para o surgimento de palavras derivadas, é introduzida no texto verbal de Susi por causa da progressão do referente discursivo ‘jovem’, com o recategorizador avaliativo 'criminosos'. Isso se deve aos modelos cognitivos:

Os modelos são, pois, estruturas complexas de conhecimentos, que representam as experiências que vivenciamos em sociedade e que servem de base aos processos conceituais. São frequentemente representados em forma de redes, nas quais as unidades conceituais são concebidas como variáveis ou slots, que denotam características estereotípicas (defaults) e que, durante os processos de compreensão, são preenchidas com valores concretos (fillers). (KOCH, 2002, p. 44)

O subtópico 'crimes', no comentário, é um exemplo de recategorizador encapsulador, o qual sumariza o ato praticado pelos jovens infratores. O recategorizador encapsulador 'crimes' é uma informação importante para defender a redução da maioridade penal, assunto tratado no artigo da jornalista Cantanhêde.

O outro caso é a variação no vocábulo com função de determinante do nome núcleo do objeto discursivo. Este é o caso do adjetivo 'prisional', no sintagma nominal 'sistema prisional', no comentário da interactante Sonia:

\section{Exemplo 8: Comentário de Sonia ${ }^{8}$}

Estou impressionada com os argumentos usados para justificar que bandidos continuem soltos. Se o sistema prisional não presta, se está abarrotado de criminosos a solução é deixar os bandidos menores de 18 anos soltos, apavorando a sociedade??? E agora ainda colocam a AIDS como obstáculo à prisão dos menores bandidos. Bandido que mata, estupra, sequestra, etc. tem que ser preso não importa a idade que tenha. E do mesmo modo que a maioria dos menores não são bandidos, ouso dizer que a maioria dos que são bandidos dificilmente vão se regenerar. Outra coisa, prisioneiro não tem que ficar recluso sem fazer nada como acontece nas prisões brasileiras, eles têm que trabalhar pra se manter e estudar.

${ }^{8}$ Retirado de: $\underline{\text { https://www.facebook.com/pg/elianecantanhedejornalista/posts/?ref=page internal. }}$ 
A palavra 'prisional' tem função de determinante qualificador no sintagma nominal. O determinante 'prisional' possibilitou a ativação do subtópico discursivo 'prisão', recategorizador encapsulador, o qual apresenta a função gramatical de ser a palavra raiz para o surgimento de palavras derivadas como o sinônimo 'prisional', que qualifica o núcleo do 'sistema', objeto discursivo.

O exemplo 8 é um caso de ativação de uma palavra primitiva como recategorizador encapsulador de referente discursivo. Ainda no exemplo, pode ser constatada a formação de uma cadeia anafórica do encapsulador 'prisão', com função discursiva de introdutor, o qual é reativado pelas formas anafóricas recategorizadoras 'prisioneiro' e 'prisões brasileiras'.

Os exemplos citados ilustram a variação lexical nas funções discursivas anafóricas recategorização e recategorização avaliativa (TEDESCO, 2002). E estas são um perfil de variação linguística relacionada com o processo de formação de palavras, que amplia semanticamente o nome núcleo de objetos discursivos e seus determinantes, em sintagmas nominais.

O grau de utilização desses recursos textuais e gramaticais no texto verbal, em comentários, orienta para a variedade cultural, que é um critério social importante para os estudos sociolinguísticos, os quais são necessários para a compreensão do uso da língua em contexto virtual, a partir de gêneros digitais como o gênero comentário.

\section{CONSIDERAÇÕES FINAIS}

O propósito deste artigo foi realizar uma reflexão sobre a comunicação digital realizada no gênero discursivo digital comentário, o qual reflete o uso virtual da linguagem, que está estabelecida no princípio continuum, o qual prevê o uso da língua em situações sociais diversificadas que apresentam temáticas e estilos que influem na definição do padrão e do não padrão da língua.

Nesta conversa acadêmica, procurou-se destacar que o gênero digital comentário é uma superestrutura discursiva com suas características devidamente estabelecidas nas ordens micro e macrodiscursivas. Nesse sentido, as formas anafóricas diretas nos comentários aqui exemplificados demonstram a progressão temática dos textos verbais e a heterogeneidade discursiva a partir da variação do nome, núcleo de referentes textuais, e de seus determinantes - variação esta que é consequente do processo de formação de palavras, que permite a mudança de classe dos vocábulos e ainda amplia o sentido dos mesmos. A ampliação dos sentidos das palavras em formas anafóricas diretas como 'esse ministrinho’ demonstrou a transformação argumentativa ocorrida no comentário do interactante Marcos. É a consciência linguística, instrumentalizada pela gramática, sendo usada em benefício da interação pela linguagem.

$\mathrm{O}$ uso da linguagem em contexto digital e social abre caminhos para muitas reflexões fundamentadas que visem torná-lo objeto de pesquisa para neutralizar percepções que ainda restringem tal uso a um desvio da escrita formal. Estamos diante de um uso híbrido e hipertextual da linguagem que está pautado no princípio da interação social (KOCH, 2002), a qual é realizada e concretizada em textos orais, escritos e virtuais. 


\section{REFERÊNCIAS}

BAKHTIN, M. M. Estética da criação verbal. Tradução de P. Bezerra. $5^{a}$ ed. São Paulo: WMF Martins Fontes, 2010.

BASÍLIO, Margarida. Teoria lexical. $7^{\text {a }}$ ed. $6^{a}$ impr. São Paulo: Ática, 2003.

CALVET, Louis-Jean. Sociolinguística. Uma introdução crítica. São Paulo: Parábola, 2002.

CASTELLS, Manoel. A sociedade em rede. Tradução de R. V. Majer. $6^{a}$ ed. São Paulo: Paz e Terra, 1999.

CONTE, Maria Elisabeth. Encapsulamento anafórico. In.: CAVALCANTE, M. M; RODRIGUES, B. B.; CIULLA, A. (Orgs.). Referenciação. São Paulo: Contexto, 2003, p. 191-228.

COELHO, Izete Lehmkuhl; GÖRSKI, Edair Maria; SOUZA, Christiane Maria N.; MAY, Guilherme Henrique. Para conhecer sociolinguística. São Paulo: Contexto, 2015.

FRAGOSO, Suely; RECUERO, Raquel; AMARAL, Adriana. Métodos de pesquisa para internet. Porto Alegre: Sulina, 2016.

KOCH, Ingedore G. Villaça. A coesão textual. 11ª ed. São Paulo: Contexto, 1999.

. Desvendando os segredos do texto. São Paulo: Cortez, 2002.

LÉVY, Pierre. Cibercultura. $3^{\text {a }}$ ed. São Paulo: Editora 34, 2010.

MARCUSCHI, Luiz Antônio. Da fala para a escrita: atividade de retextualização. $4^{a}$ ed. São Paulo: Cortez, 2003.

- Anáfora indireta: o barco textual e suas âncoras. In: KOCH, Ingedore G. Villaça;

; XAVIER, Antônio Carlos. Hipertextos e gêneros digitais: novas formas de construção de sentido. $3^{a}$ ed. São Paulo: Cortez, 2010.

MORATO, Edwiges Maria; BENTES, Anna Cristina (Orgs.). Referenciação e discurso. $2^{\mathrm{a}} \mathrm{ed}$. São Paulo: Contexto, 2012.

MONDANA, L.; DUBOIS, D. Construção dos objetos de discurso e categorização: uma abordagem dos processos de referenciação. In: CAVALCANTE, Mônica Magalhães; RODRIGUES, Bernadete B.; CIULLA, Alena (Orgs.). Referenciação. São Paulo: Contexto, 2003, p. 17-52.

RECUERO, Raquel. Redes sociais na internet. $2^{\mathrm{a}}$ ed. Porto Alegre: Sulina, 2014.

TEDESCO, Maria Teresa. O processo de referenciação e a construção do texto argumentativo. 2002. (Tese de Doutorado) - Curso de Linguística, Letras e Artes, Pós-Graduação Linguística, Universidade Federal do Rio de Janeiro, Rio de Janeiro, 2002.

- Educação a distância: o processo de interação e autoria em EAD na perspectiva da linguagem. In.: SIMÕES, Darcília (Org.). Semiótica, linguística e tecnologias de linguagem. Homenagem a Umberto Eco. Rio de Janeiro: Dialogarts, 2013.

VAN DIJK, Teun A. Discurso e contexto: uma abordagem sociocognitiva. Tradução de Rodolfo Ilari. São Paulo: Contexto, 2012.

Recebido em: 28/02/2019

Aprovado em: 07/06/2019

Publicado em: 28/09/2019 